\title{
Stock Liquidity and SMEs' Likelihood of Bankruptcy: Evidence from the US Market
}

\author{
Izidin El Kalak ${ }^{1, *}$, Alcino Azevedo** Robert Hudson*, Mohamad Abd Karim \\ *Kent University Business School \\ **Aston Business School \\ ${ }^{\#}$ Hull University Business School
}

\begin{abstract}
We study the association between the stock liquidity of SMEs in the US and their likelihood of bankruptcy, using a dataset that comprises information on 5,075 firms over the time period from 1984 to 2013 using the hazard model of Campbell et al. (2008). We find that less liquid stocks are associated with higher probability of bankruptcy, although there is substantial heterogeneity across industries regarding the predictive power of the liquidity measure on the likelihood of bankruptcy. Furthermore, the exchange where the SMEs are listed also affects the likelihood of bankruptcy. Classification performance tests conclude that adding a liquidity measure variable to the Campbell (2008) model improves its predictive power.
\end{abstract}

JEL classification: G12, G14.

Keywords: Market Liquidity; Liquidity Measures; Bankruptcy; Hazard Model.

\footnotetext{
${ }^{1}$ Corresponding Author: i.el-kalak@kent.ac.uk.
} 


\section{Introduction}

Stock liquidity is an important variable in financial markets. More liquid stocks are usually associated with lower transaction costs and liquidity risk premiums (see, e.g., Becker-Blease and Paul (2006), and less liquid stocks are usually associated with lower credit ratings and a higher risk of default (see, e.g., Odders-White and Ready (2006).

There are several stock liquidity measures available in the microstructure literature, such as the trading volume, share turnover, bid-ask spread, Amihud (2002) and Florackis et al. (2011) liquidity (or illiquidity) ratios. Each of these liquidity ratios captures different aspects of stocks (Chai et al., 2010).

A very simple stock liquidity measure is, for instance, trading volume. Nevertheless, it does not take into account some important stock liquidity related characteristics, for instance, price and return, and the bid-ask spread and the speed at which stock trading occurs. Consequently, other more sophisticated liquidity measures were developed, for instance, the Gabrielsen et al. (2011) liquidity ratio, which considers the trading volume and the market capitalization, and the Amihud (2002) and Florackis et al (2011) illiquidity ratios, which consider trade volume, stock return and the turnover ratio. ${ }^{2}$

In this paper we use the following stock liquidity (or illiquidity) measures: Atkins and Dyl (1997) (i.e., the zero-return measure), and Lesmond et al. (1999) (i.e., the turnover ratio), and the Amihud (2002) and Florackis et al. (2011) illiquidity ratios. We examine the relationship between stock liquidity and firm value and the probability of bankruptcy of US SMEs, using a data sample that comprises information on 5,075 US SMEs firms, over the time period between 1984 and 2013.

Extant literature suggests that higher stock liquidity is positively associated with firm value and performance and encourages the use of more efficient managerial compensation schemes (Holmström and Tirole, 1993). There are also studies suggesting that higher stock liquidity reduces managerial opportunism and direct issuing costs, and improves corporate governance (see, e.g., Maug, 1998; Edmans, 2009; Butler and Wan (2010) and Butler et al. (2005).

Studies on SMEs cover a wide range of research areas, for instance, the determinants of the SMEs' profitability and capital structure (e.g., Kolari and Shin, 2004: and Sogorb-Mira, 2005) and the SMEs' loan structure (e.g., Berger and Udell, 2004).

There are several bankruptcy prediction models available in the literature, for instance, the Altman (1968) model, based on accounting information, the Vassalou and Xing (2004) model, based on

\footnotetext{
${ }^{2}$ Chai, D., Faff, R. \& Gharghori, P. (2010), "New evidence on the relation between stock liquidity and measures of trading activity." International Review of Financial Analysis, Vol. 19, No.3: pp. 181-192., classify the liquidity measures into four categories: trading cost, price impact/depth, resilience and trading speed/frequency. Goyenko, R. Y., Holden, C. W. \& Trzcinka, C. A. (2009), "Do liquidity measures measure liquidity?" Journal of Financial Economics, Vol. 92, No.2: pp. 153-181. classify the liquidity measures into two categories: low-frequency spread proxies and low-frequency price impact proxies.
} 
contingent claims analysis, and the Shumway (2001) and Campbell et al. (2008) models, based on a survival analysis that considers both accounting and market information. In this paper we examine the relationship between stock liquidity, measured by the four liquidity measures described above and the probability of bankruptcy, using the Campbell et al. (2008) hazard model and a dataset that comprises information on 4,656 healthy SMEs and 419 bankrupt SMEs listed in the US market.

Our results show that all the above liquidity measures are negatively associated with the probability of bankruptcy, i.e., the higher the stock liquidity the less likely is the bankruptcy probability. We check the robustness of our results by using the predictive ability test and examining the area under the receiver operating characteristics curve, and both confirm that the use of a stock liquidity measure variable in the baseline Campbell et al. (2008) model improves the predicting power of the discrete-time durationdependent hazard model. Additionally, the average stock liquidity of the bankruptcies sample (419 firms) is lower than the average stock liquidity of the non-bankruptcies sample (47,233 firms). More specifically, the turnover and Amihud (2002) liquidity ratios of the bankruptcies sample are approximately 2.5 times higher than those of the non-bankruptcies sample. The Florackis (2011) liquidity ratio of the bankruptcies sample is roughly twice that of the non-bankruptcies sample, and the Zero-Return ratio of the bankruptcy sample is 1.5 times higher than that of the non-bankruptcy sample.

The remainder of the paper is organised as follows. Section 2 discusses the methodology. Section 3 describes the data sources and variables. Section 4 presents the results. Section 5 concludes.

\section{Methodology}

\subsection{Discrete-Time Duration-Dependent Hazard Model}

We use a discrete-time duration-dependent hazard method, used by Bauer and Agarwal (2014) and El Kalak and Hudson (2016), to examine the effect of stock liquidity on the probability of failure of SMEs by following the model developed by Campbell et al. (2008). Bauer and Agarwal (2014) compare the accuracy of several bankruptcy prediction models and conclude that the hazard models are more accurate than the z-score and contingent claims models, with their results still being valid when the economic value of each model is considered. Hwang (2012) shows that there are advantages in using a discrete-time duration-dependent hazard rate, since it allows, for instance, the coefficients of the firmspecific predictors to be dynamic over time. Nam et al. (2008) contend that the application of discretetime duration-dependent hazard model can be comparable to the application of a panel logistic model incorporating a macro-dependent baseline hazard.

The firm i's conditional probability of default in the time interval $t$, given it survives up to this time is given by the discrete time hazard function $(\lambda)$ :

$$
\lambda\left(t \backslash X_{i, t}\right)=\operatorname{Pr}\left(T=t \backslash T \geq t, X_{i, t}\right)
$$


where $T$ is a discrete time failure, $T=t$ means a failure within the time interval $t$, and $X_{i, t}$ is the value of covariates of firm $i$ up to the time interval $t$.

The hazard model is defined as follows:

$$
h\left(t \backslash X_{i, t}\right)=h(t \backslash 0) \cdot \exp \left\{X_{i, t}^{\prime} \beta\right\}
$$

where $h\left(t \backslash X_{i, t}\right)$ is the individual hazard rate of firm $i$ at time $t$.

The discrete hazard model suits fairly with the features of our empirical data because it is coherent with the binary nature of our model dependent variables and the time-series, and the cross-sectional nature of the dataset. In line with previous literature, we estimate our hazard models using a discrete-time framework with random effects, controlling for unobserved heterogeneity and shared frailty, given by Equation (3).

$$
P_{i, t}=\frac{e^{\alpha(t)+\beta X_{i, t}}}{1+e^{\alpha(t)+\beta X_{i, t}}}
$$

where $a(t)$ is the time-varying covariate which captures the baseline hazard rate, $\beta$ is the coefficient value of the covariate $\mathrm{x}$, and $P_{i, t}$ represents the probability that the bankruptcy of firm $i$ occurs at time $t$.

\subsection{Hazard Rate Specification}

If all the covariates are equal to zero, there are numerous techniques to proxy the baseline hazard function, a $(\mathrm{t})$, for instance, using the $\log \left(t^{\prime}\right)$, where $t^{\prime}$ is the survival period, a polynomial in survival time, a fully non-parametric, or the piece-wise constant (Jenkins, 2005). In order to choose the most appropriate method, we have to estimate and analyse first the survival and the hazard curves.

Figure 1A shows that the survival probability as a function of the firms' age, estimated using the Kaplan-Meier estimator, and our sample average survival probability decreases to around 0.85 as firms' age increases reaching twenty years, being henceforth more or less constant. We estimate the hazard model curve to decide about the appropriate method to be used to determine the baseline hazard.

Figure 1B shows the hazard rate curve as a function of the firms' age, where we can see that the hazard rates differ significantly according to the age groups. Therefore, we use a fully non-parametric baseline hazard model with age dummy variables to define the baseline hazard rate (Jenkins, 2005). The number of age-specific dummies is equal to the maximum survival time of the dataset (i.e., 29 years), nevertheless, we generate 28 age-dummies to avoid perfect multicollinearity that can arise from the dummy variable trap.

\section{[Insert Figure 1 here]}




\subsection{Robustness Tests}

\subsubsection{Predictive Ability Test}

To test the models predictive ability, we carry out a bankruptcy out-of-sample prediction test, parallel to that used by Shumway (2001), on the period (2009-2013), and re-calculate our estimations made on data for the time period between 1984 and 2008. Subsequently, we rank firms into deciles, year by year, according to the bankruptcy probabilities, where firms that are more probable to default in the next year are in the first decile. Then we determine for each decile the percentage of firms that have defaulted. The model with the best performance is the one that has a higher percentage of defaults in the top deciles.

\subsubsection{Receiver Operating Characteristics Curve}

The receiver operating characteristics curve (ROC) is a widely used measure for evaluating the accuracy of the predictive power of a model. ROC curves identify the true positive rate against the false positive rate as the threshold to discriminate changes between solvent and insolvent firms. The area under the ROC curve (AUROC) indicates the accuracy of the predictive power of the model, where " 1 " means a perfect model (Anderson, 2007).

\section{Data Sample and Regression Variables}

\subsection{Data Sample}

Our dataset comprises information on SMEs bankruptcies for the US market over the time period between 1984 and 2013. We define an SMEs firm as a firm with no more than 500 employees and an average yearly turnover below $\$ 7.5$ million. ${ }^{3}$ We use two main sources for the data collection: the Compustat security database, for stock prices, trading volumes and shares outstanding, and the Compustat-Fundamentals Annual database, for accounting information.

In line with previous studies, we exclude the SMEs operating in the financial, insurance and utility sectors. The SMEs operating in the financial, insurance that were eliminated from our sample have industrial classification (SIC) codes that range between 6,000 and 6,999. The SMEs operating in regulated utility markets have industry codes are between 4,900 and 4,949. We also removed from our sample non-US firms and observations with missing data regarding the control variables or dependent variables. Our final data sample comprises information on 4,656 healthy firms and 419 bankrupt firms and our panel data has 47,652 observations.

To eliminate the possibility of any wrong entries in our sample, we only consider observations with positive values for the common equity, total assets, stock price at the end of the fiscal year and number of shares outstanding. We control for the industry effect by categorising the SMEs into nine distinctive industry categories, and extreme outliers were eliminated. We winsorised our independent variables

\footnotetext{
${ }^{3}$ For further details see "Small Business Administration” (SBA). https://www.sba.gov/.
} 
between the $5^{\text {th }}$ and the $95^{\text {th }}$ percentiles and lagged the covariates by one-time period to ensure that the information used was available at the beginning of the time periods.

Table 2 shows the distribution of our data sample over time sample time period.

\section{[Insert Table 2 here]}

Among other information, the above results reveal that between 1989 and 1993 the percentage of bankruptcies was significantly higher than for the rest of the sample time period and that the percentage of bankruptcies has been decreasing gradually since 1991.

\section{[Insert Figure 2 here]}

Table 3 shows how the 419 identified bankruptcies are distributed across industries and reveals that the manufacturing industry is the industry where there is a higher percentage of bankruptcies, $40.8 \%$, followed by the Public Administration, Services, and Mineral industries, with 17.2\%, 14.8\%, and 11.2\%, respectively.

\section{[Insert Table 3 here]}

Table 4 shows how the 419 bankruptcies are distributed across the Stock Exchanges where the SMEs are listed. We conclude that most of the bankruptcies are related to firms that are not listed on the NYSE, AMEX, and NASDAQ.

\section{[Insert Table 4 here]}

\subsection{Regression Variables}

\subsubsection{Dependent variable}

According to our methodology, an SME fails if it files for legal bankruptcy proceedings (i.e., chapters 7 and 11). In the Compustat database firms are classified as bankrupt if they have a "TL" footnote on the status alert (i.e., Data item STALT), indicating that the firm is in a process of bankruptcy or liquidation. Therefore, our dependent variable takes the form of a binary variable which equals " 1 " if a firm is classified as bankrupt and "0" otherwise.

\subsubsection{Liquidity Measures}

The liquidity of a stock is characterized by its resiliency, tightness, and depth. The resiliency refers to the speed at which the stock prices bounce back to equilibrium after a large trade, the tightness refers to the transaction costs, i.e., the bid-ask spread, and the depth refers to the ability of the market to absorb a large quantity of trade without affecting significantly the market price.

Following previous studies, for instance, those of Fang et al. (2009)) and Hasbrouck (2009), we select common stocks, stocks that have at least 200 active trading days in a year, and the exchange, ticker, symbol, or CUSIP does not change over the year. For the zero ratio of liquidity, we do not consider 
stocks where the number of missing daily returns or zero daily returns exceeds 80 per cent of the annual trading days.

\subsubsection{Turnover Ratio}

The stock turnover ratio is often used to represent the average holding period of stocks (Atkins and Dyl, 1997). It is defined as the ratio of the number of shares traded to the number of shares outstanding, and determined as follows:

$$
\text { Turnover }_{i, y}=\frac{1}{D_{i, y}} \sum_{d=1}^{D_{i, y}} \operatorname{Vol}_{i, d, y} / \text { Share }_{i, d, y}
$$

where $\operatorname{Vol}_{i, d, y}$ is the trading volume for stock $i$ in day $d$ of year $\mathrm{y}$, Share $_{i, d, y}$ is the number of shares outstanding for stock $i$ in day $d$ of year $y$, and $D_{i, y}$ is the number of daily observations for stock $i$ in year $y$.

The smaller the turnover ratio, the longer is the average holding periods, therefore, there is a positive relationship between the turnover ratio and the stock liquidity.

\subsubsection{Amihud (2002) illiquidity ratio}

The Amihud (2002) illiquidity ratio is defined as follows:

$$
\operatorname{RtoV}_{i y}=\frac{1}{D_{i y}} \sum_{d=1}^{D_{i y}}\left(\frac{\left|R_{i d y}\right|}{V_{i d y}}\right)
$$

where $R_{i d y}$ and $V_{i d y}$ are, respectively, the return and the monetary trade volume of stock $i$ on day $d$ at year $y$, and $D_{i y}$ is the number of observations days in year $y$ for stock $i$.

This ratio measures the absolute percentage price change per dollar of daily trading volume or the daily price impact of the order flow. It measures directly the impact of a monetary unit of trading volume on the stock return and, therefore, the greater the reaction of the stock's return to a unit change in the trading volume, the more illiquid is the stock.

\subsubsection{Florackis et al. (2011) illiquidity ratio}

It has been noticed that the Amihud (2002) illiquidity ratio neglects the trading frequency dimension of stock liquidity. According to Grossman and Miller (1988), the illiquidity ratio is usually obtained based on averaged price changes and averaged trading volume from the past and, therefore, cannot answer the question of how the stock price is influenced by the sudden arrival of a large trade. In addition, Cochrane (2005) highlights the fact that the Amihud (2002) ratio is much higher for small capitalization stocks, which would mean that small capitalization stocks are automatically more illiquid than big capitalization stocks. Based on this criticisms, Florackis et al. (2011) suggest an alternative illiquidity ratio that considers the stock's trading volume instead of the stock's turnover ratio, determined as follows: 


$$
\operatorname{RtoTR}_{i, d, y}=\frac{1}{D_{i, y}} \sum_{D=1}^{D_{i t}}\left(\frac{\left|R_{i, d, y}\right|}{T R_{i, d, y}}\right)
$$

where $R_{i, d, y}$ and $D_{i, y}$ are defined as above.

\subsubsection{Zero-return illiquidity ratio}

The illiquidity ratio (Lesmond et al. (1999) is based on the number of days with zero return divided by the number of trading days, determined as follow:

$$
\text { Zero }_{i, y}=\frac{\text { ZeroReturn }_{i, y}}{\text { TradingDay }_{i, y}}
$$

where ZeroReturn $i, y$ is the number of days with zero return for stock $i$ over in year $y$, and TradingDay $_{i, y}$ is the number of trading days for stock $i$ in year $y$.

\subsubsection{Control variables}

Bauer and Agarwal (2014) tested the Taffler (1983) z-score model, the hazard models of (Shumway, 2001; Campbell et al., 2008), and the contingent claims model of Bharath and Shumway (2008), using a dataset comprising information on all non-financial firms listed on the London Stock Exchange over the time period between 1979 and 2009. They used the ROC curve and the information content test to assess the accuracy of each of the above models and they conclude that the hazard models are superior. We use the hazard model of Campbell et al. (2008) as our baseline model for the estimation of the probability of bankruptcy.

\section{Results}

In this section we conduct a correlation test followed by an analysis of the descriptive statistics, perform a univariate analysis of each individual covariate in our list and provide our robustness tests results. We show our results for the multivariate models, for each liquidity measure and the Campbell model, and highlight the differences among models.

\subsection{Correlation Matrix and Descriptive Statistics}

Table 5 shows the correlation matrix for the variables in our regression model. It shows that all the correlation coefficients are statistically significant at the $5 \%$ level. Nonetheless, there is are low correlation coefficient between all pairs of variables except between the Amihud and the Florakis liquidity ratios (with a coefficient of 0.66 ).

\section{[Insert Table 5 here]}

In order to get a preliminary insight about any possible biases and variability that might arise among the variables in the multivariate models, we provide a summary of the descriptive statistics of the covariates used. Table 6 shows the mean and standard deviation for the bankruptcies and non- 
bankruptcies sub-samples, as well as for the full sample. It shows that the liquidity measures for the bankruptcies sub-sample are higher than those for the non-bankruptcies sub-sample, which is in line with our expectation that firms with more illiquid stocks are more likely to go into bankruptcy. We find that the Amihud (2002) and the turnover ratios are roughly 2.5 times higher in the bankruptcies subsample than in the non-bankruptcies sub-sample, the Florackis et al. (2011) ratio for the bankruptcies sub-sample is twice as that for the non-bankruptcies sub-sample, and the Zero-return ratio of the bankruptcies sub-sample is 1.5 times that of the non-bankruptcies sample.

We conclude, therefore, that the stock liquidity is a good complementary variable to be taken into account when estimating the probability of SMEs bankruptcy.

\section{[Insert Table 6 here]}

\subsection{Univariate Analysis}

Univariate analysis has been extensively advocated and employed in the literature to gain a preliminary insight of the discriminate power of the explanatory variables (Nam et al., 2008; Altman et al., 2010). In Table 7 we show our results for the univariate analysis estimated using the discrete hazard models for each covariate. We find that all the covariates are statistically significant in discriminating between bankrupt and nonbankrupt SMEs, and the all the covariate coefficients have the expected sign.

\section{[Insert Table 7 here]}

\subsection{Discrete-time Duration-dependent Hazard Models}

Table 8 shows our estimations for discrete-time duration-dependent hazard models, where the first model, includes the Amihud (2002) ratio, the second model, includes the Florakis et al. (2011) ratio, the third model, includes the Turnover ratio, and the fourth model includes the Zero-Return liquidity ratio. We use the Campbell et al. (2008) model as a baseline model where none of the above liquidity variables are included. We find that all liquidity measures have a positive relationship with the probability of failure, which indicates that less liquid stocks are associated with higher bankruptcy probability. Among all the liquidity ratios, the Amihud (2002) is the one with the highest statistical significance. In addition, the goodness of fit measures AIC and BIC, show that the Amihud (2002) model provides the best goodness of fit. ${ }^{4}$

\section{[Insert Table 8 here]}

\subsection{Robustness Tests}

Table 9 shows our results for the predictive ability test. We conclude that the Amihud (2002) model provides the highest classification performance, with roughly $60 \%$ discriminatory power for the top

\footnotetext{
${ }^{4}$ Note that the lower the value of AIC, the better is the model's fit.
} 
three deciles. The Florackis et al. (2011), Turnover, and Zero-return liquidity ratios provide a discriminatory power of roughly $57 \%, 54 \%$, and $56 \%$, respectively, and the discriminatory power of the Campbell (2008) model is about 54\%. This means that adding a liquidity measure into the Campbell model increases its classification performance and helps to give better predictions for bankruptcy probability.

\section{[Insert Table 9 here]}

The above findings are supported by the results provided in Figure 3, which show the area under the receiver operating characteristics curve (AUROC). The Amihud (2002) ratio has the highest within and out-of-sample AUROC, with values of 0.76 and 0.75, respectively, which show that it has a higher discriminatory performance than the other ratios. The Florakis (2011) ratio has the second best performance in terms of the robustness tests, with an AUROC value of 0.76 and 0.74 within and out of sample, respectively. The within and out of sample AUROC values for the Campbell model are the lowest among the models tested, which corroborates the view that the stocks' liquidity variable when included in the bankruptcy models, enhances their predictive power.

\section{[Insert Figures 3-7]}

\section{Conclusion}

Our results show that the liquidity of the stocks in the bankruptcies sample is lower than that of those in the non-bankruptcies sample. The relationship is robust across multiple liquidity measures. The Amihud's and turnover ratios are approximately 2.5 times higher in the bankruptcies sample, the Florackis ratio of the bankruptcies sample is twice as high as that of the non-bankruptcies sample, and the Zero-Return ratio is 1.5 times higher. All the liquidity ratios support the hypothesis that firms with more illiquid stocks are more likely to enter into a bankruptcy process.

Our classification performance test concluded that adding a liquidity measure variable to the model of Campbell (2008) helps to improve its predictive power. Estimation of the discrete-time durationdependent hazard models incorporating four different liquidity ratios confirm our expectations that each liquidity measure enjoys a positive relationship with the probability of failure indicating that less liquid stocks are associated with higher probability of bankruptcy. 


\section{References}

Altman, E. I., Sabato, G. \& Wilson, N. (2010), "The value of non-financial information in small and medium-sized enterprise risk management." The Journal of Credit Risk, Vol. 6, No.2: pp. 95127.

Amihud, Y. (2002), "Illiquidity and stock returns: cross-section and time-series effects." Journal of Financial Markets, Vol. 5, No.1: pp. 31-56.

Anderson, R. (2007), "The Credit Scoring Toolkit: Theory and Practice for Retail Credit Risk Management and Decision Automation," Oxford University Press.

Atkins, A. B. \& Dyl, E. A. (1997), "Transactions costs and holding periods for common stocks." The Journal of Finance, Vol. 52, No.1: pp. 309-325.

Bauer, J. \& Agarwal, V. (2014), "Are hazard models superior to traditional bankruptcy prediction approaches? A comprehensive test." Journal of Banking \& Finance, Vol. 40, No.0: pp. 432442.

Becker-Blease, J. R. \& Paul, D. L. (2006), "Stock liquidity and investment opportunities: Evidence from index additions." Financial Management, Vol. 35, No.3: pp. 35-51.

Bharath, S. T. \& Shumway, T. (2008), "Forecasting Default with the Merton Distance to Default Model." The Review of Financial Studies, Vol. 21, No.3: pp. 1339-1369.

Butler, A. W., Grullon, G. \& Weston, J. P. (2005), "Stock market liquidity and the cost of issuing equity." Journal of Financial and Quantitative Analysis, Vol. 40, No.02: pp. 331-348.

Butler, A. W. \& Wan, H. (2010), "Stock market liquidity and the long-run stock performance of debt issuers." Review of Financial Studies, Vol. 23, No.11: pp. 3966-3995.

Campbell, J. Y., Hilscher, J. \& Szilagyi, J. (2008), "In Search of Distress Risk." The Journal of Finance, Vol. 63, No.6: pp. 2899-2939.

Chai, D., Faff, R. \& Gharghori, P. (2010), "New evidence on the relation between stock liquidity and measures of trading activity." International Review of Financial Analysis, Vol. 19, No.3: pp. 181-192.

Cochrane, J. H. (2005), Asset pricing program review: Liquidity, trading and asset prices. NBER Reporter, Winter.

El Kalak, I. \& Hudson, R. (2016), "The effect of size on the failure probabilities of SMEs: An empirical study on the US market using discrete hazard model." International Review of Financial Analysis, Vol. 43, No.1: pp. 135-145.

Fang, V. W., Noe, T. H. \& Tice, S. (2009), "Stock market liquidity and firm value." Journal of Financial Economics, Vol. 94, No.1: pp. 150-169.

Florackis, C., Gregoriou, A. \& Kostakis, A. (2011), "Trading frequency and asset pricing on the London Stock Exchange: Evidence from a new price impact ratio." Journal of Banking \& Finance, Vol. 35, No.12: pp. 3335-3350.

Goyenko, R. Y., Holden, C. W. \& Trzcinka, C. A. (2009), "Do liquidity measures measure liquidity?" Journal of Financial Economics, Vol. 92, No.2: pp. 153-181.

Grossman, S. J. \& Miller, M. H. (1988), "Liquidity and market structure." Journal of Finance, Vol. 43, No.3: pp. 617-633.

Hasbrouck, J. (2009), "Trading Costs and Returns for U.S. Equities: Estimating Effective Costs from Daily Data." The Journal of Finance, Vol. 64, No.3: pp. 1445-1477.

Hwang, R.-C. (2012), "A varying-coefficient default model." International Journal of Forecasting, Vol. 28, No.3: pp. 675-688. 
Jenkins, S. P. (2005), Survival analysis. Unpublished manuscript, Institute for Social and Economic Research, University of Essex, Colchester, UK.

Lesmond, D. A., Ogden, J. P. \& Trzcinka, C. A. (1999), "A new estimate of transaction costs." Review of Financial Studies, Vol. 12, No.5: pp. 1113-1141.

Nam, C. W., Kim, T. S., Park, N. J. \& Lee, H. K. (2008), "Bankruptcy prediction using a discrete-time duration model incorporating temporal and macroeconomic dependencies." Journal of Forecasting, Vol. 27, No.6: pp. 493-506.

Odders-White, E. R. \& Ready, M. J. (2006), "Credit ratings and stock liquidity." Review of Financial Studies, Vol. 19, No.1: pp. 119-157.

Shumway, T. (2001), "Forecasting Bankruptcy More Accurately: A Simple Hazard Model." The Journal of Business, Vol. 74, No.1: pp. 101-124.

Taffler, R. J. (1983), "The assessment of company solvency and performance using a statistical model." Accounting and Business Research, Vol. 13, No.52: pp. 295-308. 
Table 1: Definition of the regression model variables.

\begin{tabular}{|c|c|c|}
\hline Variable & Definition & Expected Sign \\
\hline \multicolumn{3}{|c|}{ Dependent variable } \\
\hline Fail & $\begin{array}{l}\text { Dummy variable that is equal to one if a company enters } \\
\text { insolvency procedures and zero otherwise. }\end{array}$ & \\
\hline \multicolumn{3}{|c|}{ Independent Variables } \\
\hline \multicolumn{3}{|c|}{ 1. Accounting variables } \\
\hline NIMTA & Net income to market-valued total assets (Profitability) & $(-)$ \\
\hline TLMTA & $\begin{array}{l}\text { Total liabilities relative to market-valued total assets } \\
\text { (Leverage) }\end{array}$ & $(+)$ \\
\hline CASHMTA & Cash over market-valued total assets (Liquidity) & $(-)$ \\
\hline MB & $\begin{array}{l}\text { The ratio of book value of total assets minus the book value } \\
\text { of equity plus the market value of equity to book value of } \\
\text { assets (Market to book value) }\end{array}$ & $(-)$ \\
\hline \multicolumn{3}{|c|}{ 2. Market Variables } \\
\hline RSIZE & $\begin{array}{l}\text { Logarithm of the firm's size over the aggregate market } \\
\text { value of the S\&P } 500 \text { index }\end{array}$ & $(-)$ \\
\hline EXRET & $\begin{array}{l}\text { Logarithm of the excess return over the s S\&P } 500 \text { "Return } \\
\text { Index = RI" }\end{array}$ & $(-)$ \\
\hline SIGMA & Standard deviation of daily return over the past 3 months & $(+)$ \\
\hline PRICE & $\begin{array}{l}\text { Log of Unadjusted or raw stock price and denominated in } \\
\text { pence }\end{array}$ & $(-)$ \\
\hline
\end{tabular}


Table 2: The sample distribution over time. Columns (2) and (4) show for each year the number of firms which are bankrupt and the number of firms which are not bankrupt, respectively. Columns 3 and 5 show for each year the percentages of firms which are bankrupt and not bankrupt, respectively. Column 6 shows for each year the total observations of our sample.

\begin{tabular}{|c|c|c|c|c|c|}
\hline Year & $\begin{array}{l}\text { Bankruptcies } \\
\text { (n) }\end{array}$ & $\begin{array}{l}\text { Bankruptcies } \\
\text { (\%) }\end{array}$ & Non-bankruptcies & $\begin{array}{l}\text { Non-bankruptcies } \\
\text { (\%) }\end{array}$ & Full Sample \\
\hline 1984 & 11 & 0.96 & 1,135 & 99.04 & 1,146 \\
\hline 1985 & 10 & 0.84 & 1,176 & 99.16 & 1,186 \\
\hline 1986 & 11 & 0.90 & 1209 & 99.10 & 1,220 \\
\hline 1987 & 13 & 0.99 & 1290 & 99.00 & 1,303 \\
\hline 1988 & 15 & 0.99 & 1487 & 99.00 & 1,502 \\
\hline 1989 & 17 & 1.24 & 1354 & 98.76 & 1,371 \\
\hline 1990 & 31 & 2.17 & 1395 & 97.83 & 1,426 \\
\hline 1991 & 27 & 1.80 & 1473 & 98.20 & 1,500 \\
\hline 1992 & 20 & 1.36 & 1456 & 98.65 & 1,476 \\
\hline 1993 & 21 & 1.43 & 1451 & 98.57 & 1,472 \\
\hline 1994 & 17 & 1.08 & 1561 & 98.92 & 1,578 \\
\hline 1995 & 15 & 0.88 & 1698 & 99.12 & 1,713 \\
\hline 1996 & 22 & 1.23 & 1767 & 98.77 & 1,789 \\
\hline 1997 & 17 & 0.93 & 1815 & 99.07 & 1,832 \\
\hline 1998 & 19 & 0.99 & 1892 & 99.01 & 1,911 \\
\hline 1999 & 14 & 0.72 & 1935 & 99.28 & 1,949 \\
\hline 2000 & 9 & 0.40 & 2254 & 99.60 & 2,263 \\
\hline 2001 & 16 & 0.74 & 2135 & 99.26 & 2,151 \\
\hline 2002 & 13 & 0.64 & 2013 & 99.36 & 2,026 \\
\hline 2003 & 15 & 0.70 & 2135 & 99.30 & 2,150 \\
\hline 2004 & 17 & 0.81 & 2086 & 99.19 & 2,103 \\
\hline 2005 & 13 & 0.71 & 1813 & 99.29 & 1,826 \\
\hline 2006 & 11 & 0.62 & 1758 & 99.38 & 1,769 \\
\hline 2007 & 6 & 0.35 & 1692 & 99.65 & 1,698 \\
\hline 2008 & 7 & 0.46 & 1502 & 99.54 & 1,509 \\
\hline 2009 & 9 & 0.63 & 1423 & 99.37 & 1,432 \\
\hline 2010 & 7 & 0.56 & 1234 & 99.44 & 1,241 \\
\hline 2011 & 4 & 0.35 & 1145 & 99.65 & 1,149 \\
\hline 2012 & 6 & 0.59 & 1004 & 99.41 & 1,010 \\
\hline 2013 & 6 & 0.63 & 945 & 99.37 & 951 \\
\hline Total & 419 & 0.88 & 47,233 & 99.12 & 47,652 \\
\hline
\end{tabular}


Table 3: The construction of industry-codes. The SIC codes are provided in column 1, the corresponding Industry is shown in column 2 and the respective industry names are given in column 3. In columns 4 and 5 we provide the number and the percentage of bankruptcies for each industry over the sample time-period (1984 - 2013).

\begin{tabular}{lllrr}
\hline $\begin{array}{l}\text { IND } \\
\text { Code }\end{array}$ & $\begin{array}{l}\text { SIC } \\
\text { code }\end{array}$ & $\begin{array}{l}\text { Industry } \\
\text { Name }\end{array}$ & Bankruptcies (n) & Bankruptcies (\%) \\
\hline 1 & $<1000$ & Agriculture, Forestry and Fisheries & 2 & $0.48 \%$ \\
2 & 1000 to less than 1500 & Mineral Industries & 47 & $11.22 \%$ \\
3 & 1500 to less than 1800 & Construction Industries & 9 & $2.15 \%$ \\
4 & 2000 to less than 4000 & Manufacturing & 171 & $40.81 \%$ \\
5 & 4000 to less than 4899 & Transportation and & 9 & $2.15 \%$ \\
6 & 4950 to less than 5200 & Communications & 15 & $3.58 \%$ \\
7 & 5200 to less than 6000 & Retail Trade & 32 & $7.64 \%$ \\
8 & 7000 to less than 8900 & Service Industries & 62 & $14.80 \%$ \\
9 & 9100 to less than 10000 & Public Administration & 72 & $17.18 \%$ \\
\hline & & Total Bankruptcies & 419 & $100.00 \%$ \\
\cline { 2 - 4 }
\end{tabular}


Table 4: The number and percentage of bankruptcies in our sample by the Stock Exchange where the firms are listed.

\begin{tabular}{lrr}
\hline Stock Exchange & Bankruptcies (n) & Bankruptcies (\%) \\
\hline NYSE & 21 & $5.01 \%$ \\
AMEX & 9 & $2.15 \%$ \\
OTC Bulletin Board & 140 & $33.41 \%$ \\
NASDAQ & 23 & $5.49 \%$ \\
Other OTC & 226 & $53.94 \%$ \\
\hline Total Bankruptcies & 419 & $100 \%$ \\
\hline
\end{tabular}


Table 5: The correlation coefficients between the variables used in our regression models, where ***, **, and * indicate that the correlation coefficient is significant at $1 \%, 5 \%$, and $10 \%$ level respectively.

\begin{tabular}{|c|c|c|c|c|c|c|c|c|c|c|c|}
\hline & Amihud & Florakis & Turnover & Zero-return & NIMTA & TLTMA & EXRET & RSIZE & SIGMA & CASHMTA & $\mathrm{MB}$ \\
\hline Amihud & 1 & & & & & & & & & & \\
\hline Florakis & $0.66^{* *}$ & 1 & & & & & & & & & \\
\hline Turnover & $0.03 * *$ & $0.04 * *$ & 1 & & & & & & & & \\
\hline Zero-Return & $0.21^{* *}$ & $0.21 * *$ & $0.05^{* *}$ & 1 & & & & & & & \\
\hline NIMTA & $-0.03 * *$ & $-0.08^{* *}$ & $-0.02 * *$ & $-0.10^{* *}$ & 1 & & & & & & \\
\hline TLTMA & $0.20^{* *}$ & $0.18^{* *}$ & $0.04^{* *}$ & $0.27 * *$ & $0.05^{* *}$ & 1 & & & & & \\
\hline EXRET & $-0.03 * *$ & $-0.01^{* *}$ & $-0.02 * *$ & $-0.05^{* *}$ & $0.42 * *$ & $0.07 * *$ & 1 & & & & \\
\hline RSIZE & $-0.32 * *$ & $-0.39 * *$ & $-0.06^{* *}$ & $-0.37 * *$ & $0.33^{* *}$ & $-0.40^{* *}$ & $0.29 * *$ & 1 & & & \\
\hline SIGMA & $0.36 * *$ & $0.42 * *$ & $0.04 * *$ & $0.14^{* *}$ & $-0.35 * *$ & $0.20 * *$ & $-0.25^{* *}$ & $-0.56^{* *}$ & 1 & & \\
\hline CASHMTA & $-0.08^{* *}$ & $-0.13^{* *}$ & $-0.04 * *$ & $-0.10^{* *}$ & $-0.08^{* *}$ & $-0.19 * *$ & $0.09 * *$ & $0.08^{* *}$ & $-0.14^{* *}$ & 1 & \\
\hline MB & $-0.19 * *$ & $-0.30^{* *}$ & $-0.02^{* *}$ & $-0.03 * *$ & $-0.12 * *$ & $-0.33 * *$ & $-0.13^{* *}$ & $-0.03^{* *}$ & $0.23 * *$ & $-0.35^{* *}$ & 1 \\
\hline
\end{tabular}


Table 6: The descriptive statistics (mean and standard deviation) of the variables used in our regression model for the bankruptcies, the non-bankruptcies and the full samples and the liquidity measures.

\begin{tabular}{lcccccc}
\hline Variable & \multicolumn{2}{c}{$\begin{array}{c}\text { Bankruptcies } \\
\text { Sample }\end{array}$} & \multicolumn{2}{c}{$\begin{array}{c}\text { Non-Bankruptcies } \\
\text { Sample }\end{array}$} & \multicolumn{2}{c}{$\begin{array}{c}\text { Full } \\
\text { Sample }\end{array}$} \\
\hline & Mean & SD & Mean & SD & Mean & SD \\
\hline Liquidity Measures & & & & & & \\
\hline Amihud. (2002) & 0.02 & 0.07 & 0.01 & 0.04 & 0.01 & 0.04 \\
\hline Florakis et al. (2011) & 1.55 & 4.23 & 0.75 & 3.24 & 0.80 & 4.10 \\
\hline Turnover & 0.35 & 0.42 & 0.14 & 0.31 & 0.15 & 0.51 \\
\hline Zero-return & 0.49 & 0.29 & 0.32 & 0.26 & 0.32 & 0.26 \\
\hline Control Variables & & & & & & \\
\hline NIMTA & -0.19 & 0.24 & -0.10 & 0.18 & -0.10 & 0.18 \\
TLTMA & 0.56 & 0.31 & 0.30 & 0.25 & 0.30 & 0.26 \\
EXRET & -0.09 & 0.14 & -0.03 & 0.08 & -0.03 & 0.08 \\
RSIZE & -14.45 & 2.09 & -12.74 & 1.77 & -12.75 & 1.77 \\
SIGMA & 1.91 & 1.52 & 1.13 & 0.89 & 1.13 & 0.90 \\
CASHMTA & 0.09 & 0.16 & 0.12 & 0.15 & 0.12 & 0.15 \\
MB & 3.58 & 3.81 & 3.38 & 3.36 & 3.38 & 3.36 \\
PRICE & -1.29 & 1.88 & 0.54 & 1.71 & 0.53 & 1.72 \\
\hline
\end{tabular}


Table 7: The coefficients obtained from Univariate Regression Analysis of respective covariates. The coefficients estimated using discrete-time duration-dependent hazard function. $* * *, * *, *$ indicate that the regression coefficient is significant at $1 \%, 5 \%$, and $10 \%$ level, respectively.

\begin{tabular}{llll}
\hline \multirow{2}{*}{ Variable } & \multicolumn{2}{c}{ SMEs } \\
\cline { 2 - 4 } & Coefficient & SE & Chi^2 \\
\hline Liquidity measures & & & \\
\hline Amihud & $2.65^{* * *}$ & 0.92 & 8.19 \\
\hline Florakis & $0.10^{* * *}$ & 0.01 & 5.65 \\
\hline Turnover & $0.04^{* *}$ & 0.13 & 3.69 \\
\hline Zero-Return & $1.50^{* * *}$ & 0.35 & 17.62 \\
\hline Control variables & & & 111.34 \\
\hline NIMTA & $-3.04^{* * *}$ & 0.28 & 229.45 \\
TLTMA & $4.04^{* * *}$ & 0.26 & 108.34 \\
EXRET & $-7.29^{* * *}$ & 0.70 & 273.87 \\
RSIZE & $-0.72^{* * *}$ & 0.04 & 142.61 \\
SIGMA & $0.71^{* * *}$ & 0.05 & 12.59 \\
CASHMTA & $-1.89^{* * *}$ & 0.53 & 0.57 \\
MB & $-0.01^{* * *}$ & 0.02 & 337.53 \\
PRICE & $-0.79^{* * *}$ & 0.04 & \\
\hline
\end{tabular}


Table 8: This table reports the results of the estimations corresponding initially to the Campbell (2008) model and subsequently incorporating Amihud (2002), Florakis et al. (2011), Turnover and Zero-Return liquidity ratios. For each of this models, we report our results from the multivariate hazard analysis and the goodness of fit measures, where $* * *, * *, *$ indicate that the coefficients are significant at the $1 \%, 5 \%$, and $10 \%$ level, respectively.

\begin{tabular}{|c|c|c|c|c|c|c|c|c|c|c|}
\hline \multirow{2}{*}{ Variable } & \multicolumn{2}{|c|}{ Campbell (2008) } & \multicolumn{2}{|c|}{ Amihud (2002) } & \multicolumn{2}{|c|}{ Florakis et al. (2011) } & \multicolumn{2}{|l|}{ Turnover } & \multicolumn{2}{|l|}{ Zero-return } \\
\hline & Coefficient & SE & Coefficient & SE & Coefficient & SE & Coefficient & SE & Coefficient & $\mathrm{SE}$ \\
\hline Amihud (2002) & & & $1.83^{* * *}$ & 1.50 & & & & & & \\
\hline Florackis et al. (2011) & & & & & $0.78^{* *}$ & 0.52 & & & & \\
\hline Turnover & & & & & & & $0.33^{* *}$ & 0.23 & & \\
\hline Zero-Return & & & & & & & & & $0.09 * *$ & 0.02 \\
\hline NIMTA & $-0.96 *$ & 0.50 & $-0.95 *$ & 0.50 & $-0.87 *$ & 0.50 & $-0.96 *$ & 0.50 & -0.85 & 0.51 \\
\hline TLTMA & $3.55^{* * *}$ & 0.45 & $3.59^{* * *}$ & 0.45 & 3.67 & 0.45 & $3.54 * * *$ & 0.45 & $3.61^{* * *}$ & 0.45 \\
\hline EXRET & $-3.30 * * *$ & 0.96 & $-2.96 * * *$ & 1.00 & $-2.42 * *$ & 1.00 & $-3.33 * * *$ & 0.97 & $-3.06^{* * *}$ & 0.98 \\
\hline RSIZE & $-0.28 * * *$ & 0.12 & $-0.29 * * *$ & 0.12 & $-0.26 * *$ & 0.12 & $-0.28 * * *$ & 0.12 & $-0.31 * *$ & 0.12 \\
\hline SIGMA & $0.15^{* *}$ & 0.09 & $0.16^{*}$ & 0.09 & $0.18 * *$ & 0.09 & $0.15^{*}$ & 0.09 & 0.13 & 0.09 \\
\hline CASHMTA & 1.18 & 0.83 & 1.26 & 0.83 & 1.30 & 0.82 & 1.22 & 0.83 & 1.18 & 0.83 \\
\hline MB & 0.01 & 0.03 & 0.02 & 0.03 & 0.04 & 0.03 & 0.01 & 0.03 & 0.02 & 0.03 \\
\hline PRICE & $-0.44 * * *$ & 0.11 & $-0.45^{* * *}$ & 0.11 & $-0.54 * * *$ & 0.11 & $-0.44 * * *$ & 0.11 & $-0.45^{* * *}$ & 0.11 \\
\hline Constant & -16.49 & 3.12 & $-16.52^{* * *}$ & 3.11 & $-15.51^{* * *}$ & 3.09 & $-16.44^{* * *}$ & & -16.53 & \\
\hline Age dummies & Yes & & Yes & & Yes & & Yes & & Yes & \\
\hline Industry control & Yes & & Yes & & Yes & & Yes & & Yes & \\
\hline Exchange Control & Yes & & Yes & & Yes & & Yes & & Yes & \\
\hline Wald chi2 & 265.26 & & 272.07 & & 269.05 & & 266.22 & & 267.12 & \\
\hline Log Likelihood & -937.61 & & -931.18 & & -936.52 & & -937.11 & & -936.77 & \\
\hline AIC & 1962.23 & & 1948.36 & & 1958.05 & & 1960.23 & & 1959.54 & \\
\hline BIC & 2339.64 & & 2325.54 & & 2335.23 & & 2337.41 & & 2336.72 & \\
\hline Number of obs. & 47,652 & & 47,652 & & 47,652 & & 47,652 & & 47,652 & \\
\hline
\end{tabular}


Table 9: The classification performance of the measures provided by the Campbell (2008), Amihud (2002), Florakis et al. (2011), Turnover and Zero-Return models, over the period between 2009 and 2013. The models with better classification performance have higher percentage at the top deciles.

\begin{tabular}{llllll}
\hline Decile & Campbell (2008) & Amihud (2002) & Florakis et al. (2011) & Turnover & Zero-return \\
\hline 1 & $22.18 \%$ & $26.89 \%$ & $24.83 \%$ & $23.71 \%$ & $24.12 \%$ \\
2 & $16.52 \%$ & $17.08 \%$ & $17.75 \%$ & $16.18 \%$ & $16.97 \%$ \\
3 & $15.12 \%$ & $14.30 \%$ & $14.55 \%$ & $14.20 \%$ & $14.65 \%$ \\
4 & $12.78 \%$ & $14.44 \%$ & $11.83 \%$ & $13.47 \%$ & $12.99 \%$ \\
5 & $9.25 \%$ & $9.06 \%$ & $8.82 \%$ & $9.07 \%$ & $8.57 \%$ \\
6,10 & $24.15 \%$ & $18.23 \%$ & $22.22 \%$ & $23.37 \%$ & $22.70 \%$ \\
\hline Total & $100.00 \%$ & $100.00 \%$ & $100.00 \%$ & $100.00 \%$ & $100.00 \%$ \\
\hline \hline
\end{tabular}


Figure 1: The estimated curves based on the Kaplan-Meier estimator, where the left-hand side figure (1A) represents the survival curve and the right-hand side represents the hazard curve (1B), whereas the age of firms in years is represented by the "Age".
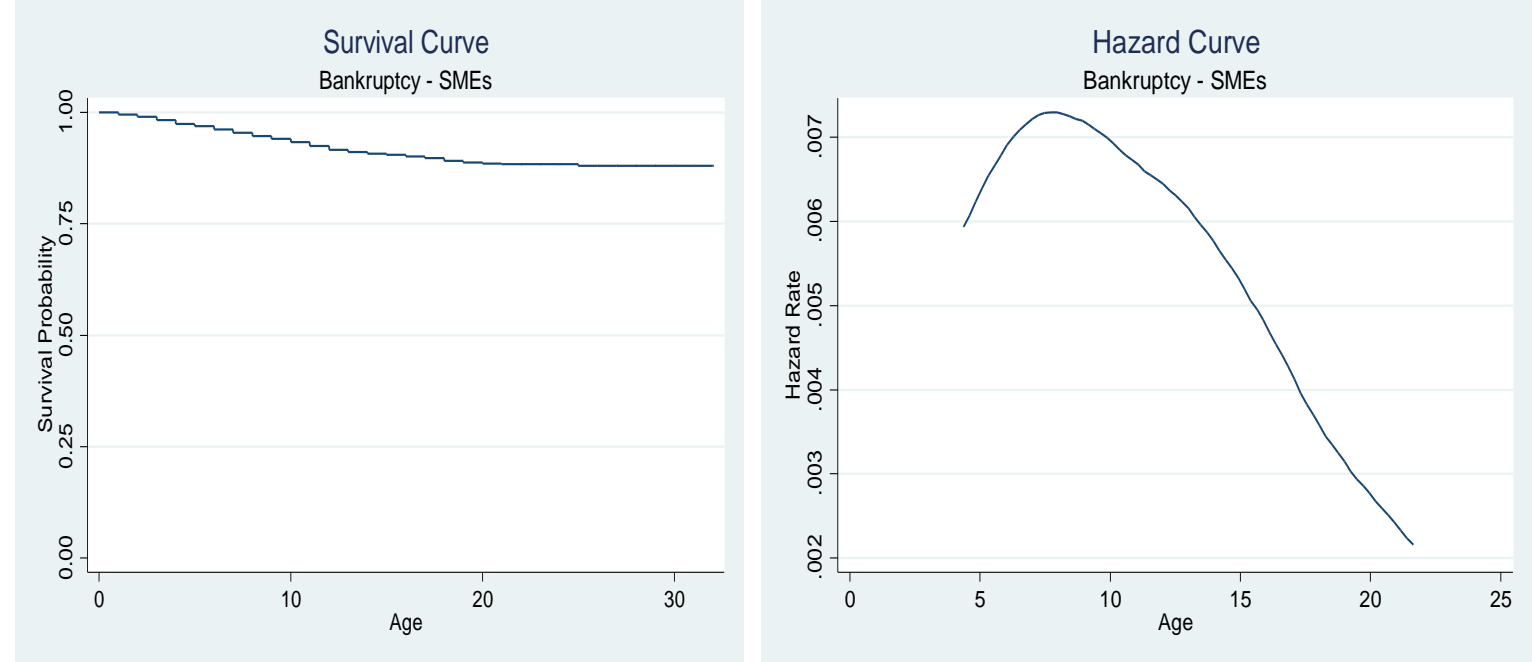
Figure 2: The evolution of the percentage of bankruptcies over the time period between 1984 and 2013.

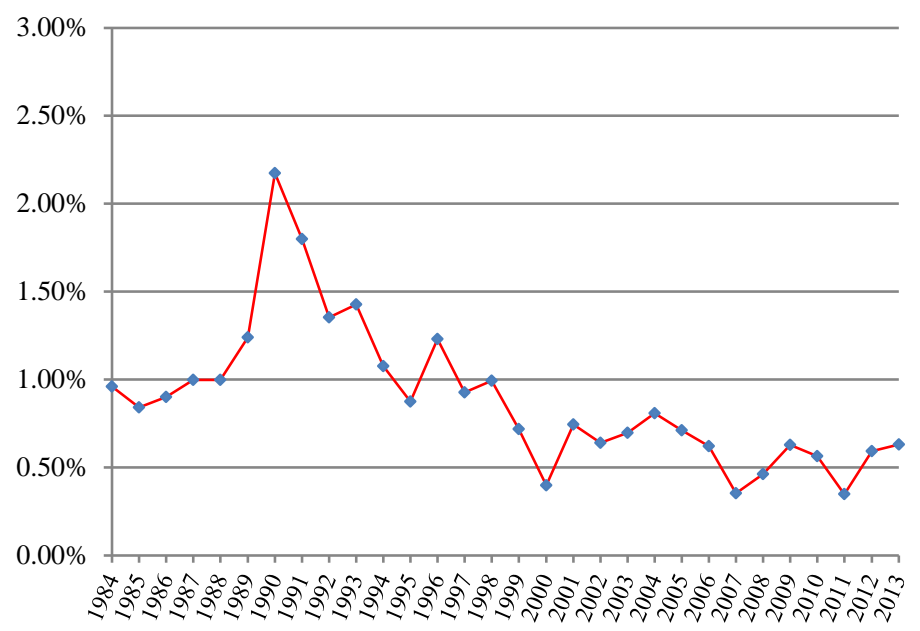


Figure 3: This figure shows the Area Under the Receiver Operating Characteristics Curve (AUROC) for the Amihud (2002) model. The left-hand side figure shows the out of sample AUROC from 2009 to 2013 and the right-hand side figure shows the within sample AUROC from 1984 to 2008.
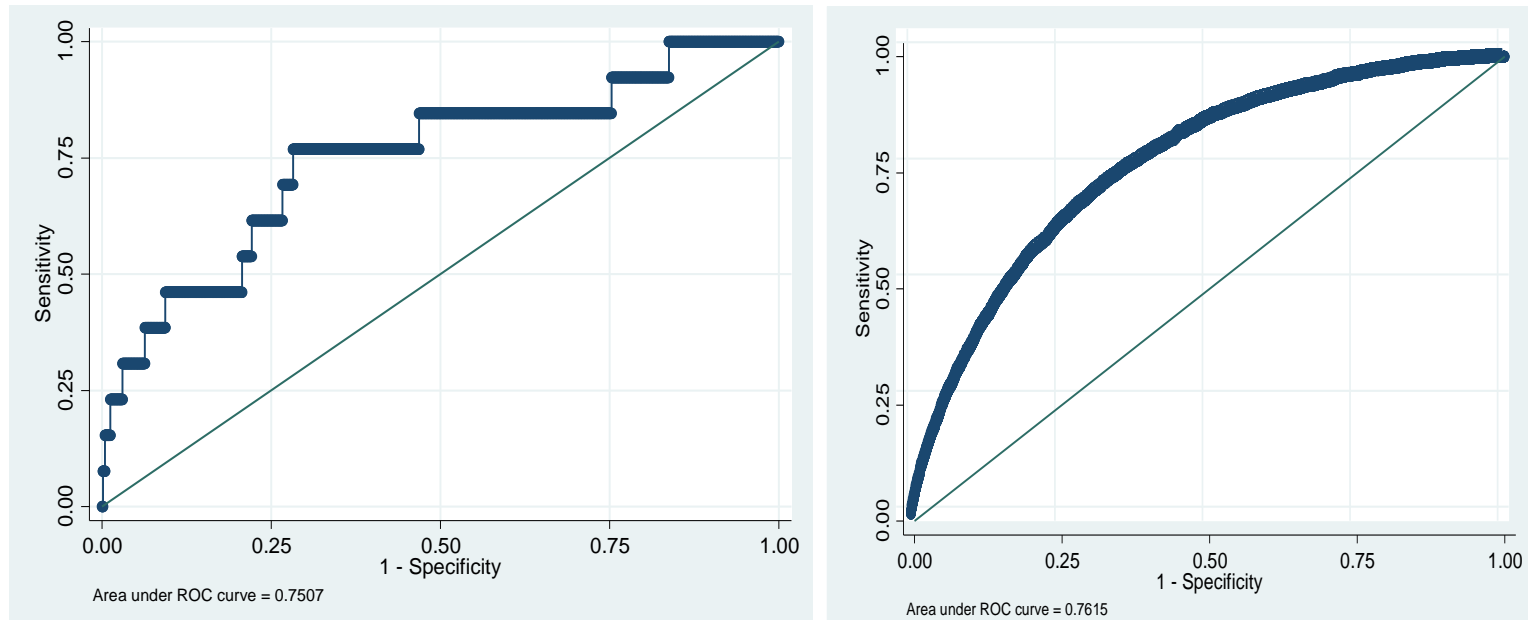

Figure 4: This figure shows the Area Under the Receiver Operating Characteristics Curve (AUROC) for the Florakis (2011) model. The left-hand side figure shows the out of sample AUROC from 2009 to 2013 and the right-hand side figure shows the within sample AUROC from 1984 to 2008.
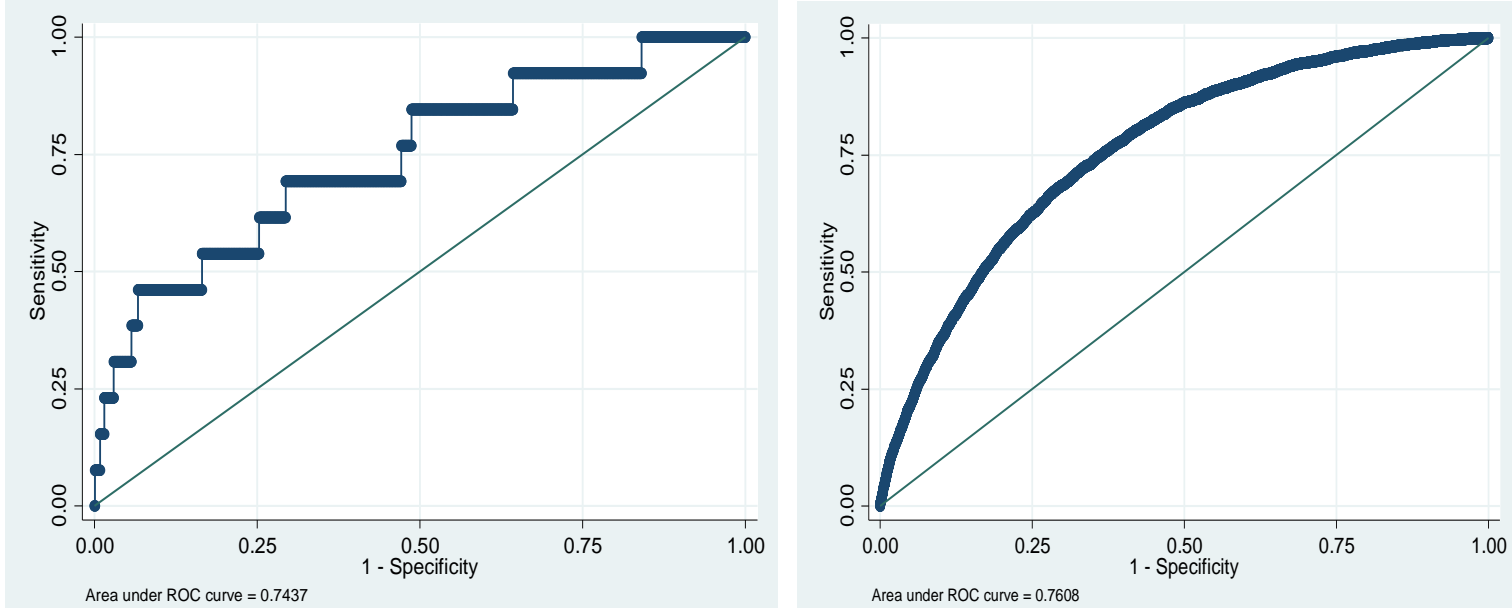
Figure 5: This figure shows the Area Under the Receiver Operating Characteristics Curve (AUROC) for the zero return model. The left-hand side figure shows the out of sample AUROC from 2009 to 2013 and the right-hand side figure shows the within sample AUROC from 1984 to 2008.
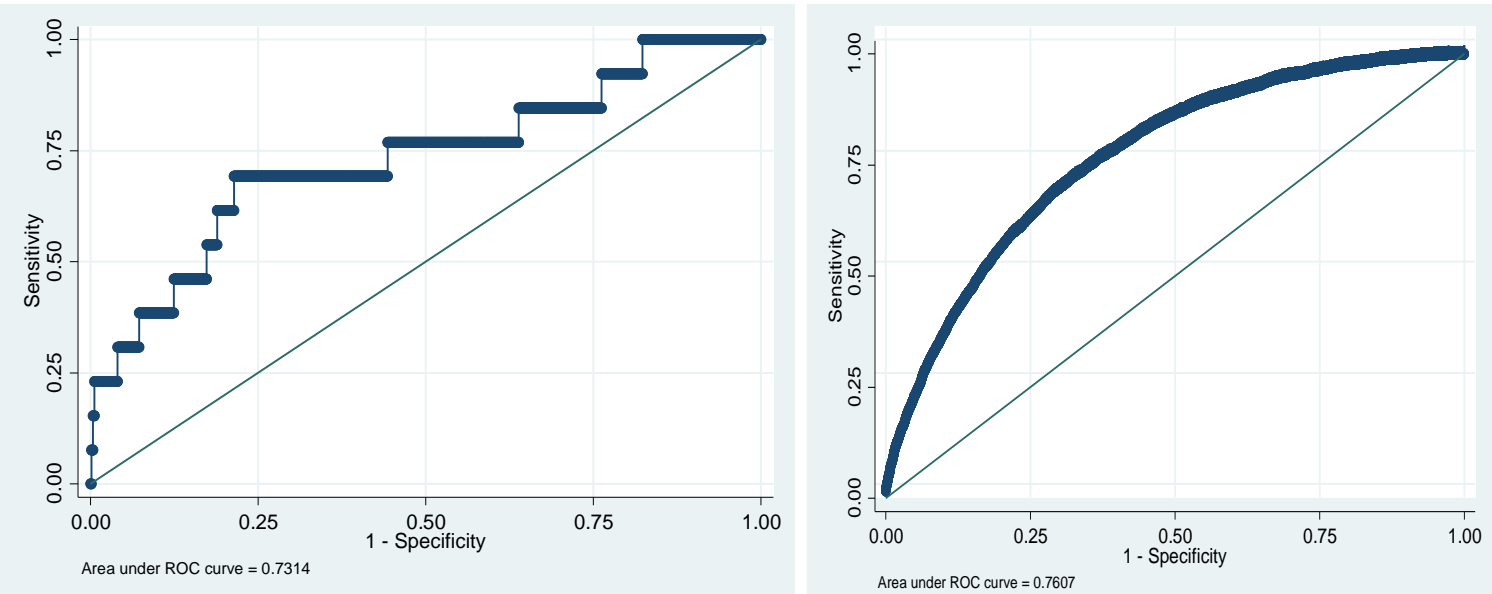

Figure 6: This figure shows the Area Under the Receiver Operating Characteristics Curve (AUROC) for the Turnover model. The left-hand side figure shows the out of sample AUROC from 2009 to 2013 and the right-hand side figure shows the within sample AUROC from 1984 to 2008.
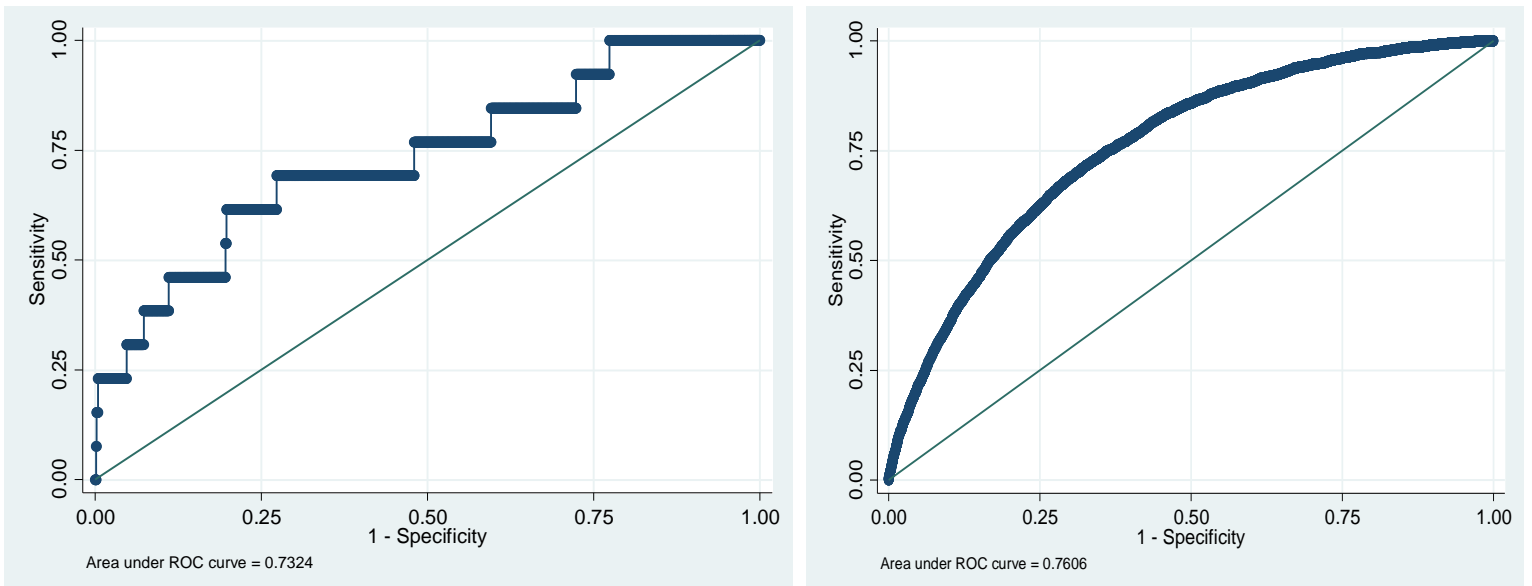
Figure 7: This figure shows the Area Under the Receiver Operating Characteristics Curve (AUROC) for the Campbell et al. (2008) model. The left-hand side figure shows the out of sample AUROC from 2009 to 2013 and the right-hand side figure shows the within sample AUROC from 1984 to 2008.
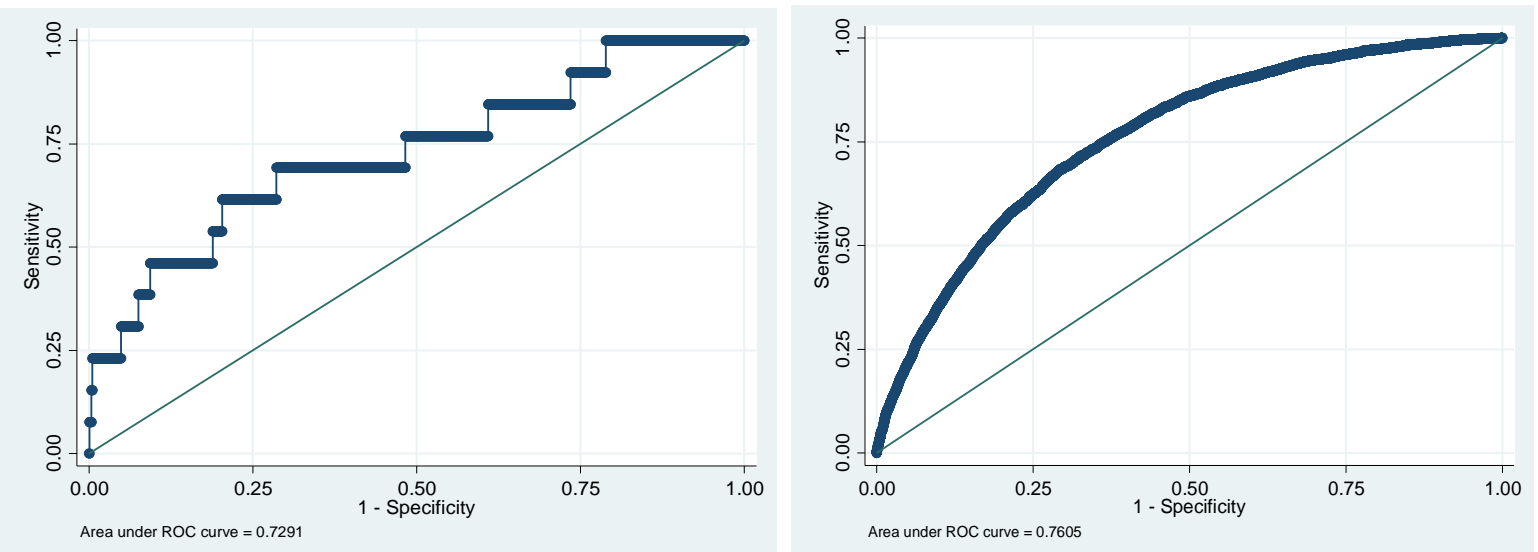